\title{
A Comparative Study of Glycerol and Urea-Modified Polyvinyl Alcohol/Oil Palm Ash Biocomposite Films
}

\author{
Zhong Xian Ooi ${ }^{1 *}$, Kam Loon Chan ${ }^{1}$, Yi Peng Teoh ${ }^{2}$ and Mathialagan Muniyadi ${ }^{2}$ \\ ${ }^{1}$ Department of Chemical Science, Faculty of Science, Universiti Tunku Abdul \\ Rahman, Jalan Universiti, Bandar Barat, 31900 Kampar, Perak, Malaysia \\ ${ }^{2}$ Department of Petrochemical Engineering, Faculty of Engineering and Green \\ Technology, Universiti Tunku Abdul Rahman, Jalan Universiti, Bandar Barat, \\ 31900 Kampar, Perak, Malaysia
}

"Corresponding author: ooizx@utar.edu.my

Published online: 31 December 2019

To cite this article: Zhong Xian Ooi, Kam Loon Chan, Yi Peng Teoh and Mathialagan Muniyadi (2019). A comparative study of glycerol and urea-modified polyvinyl alcohol/ oil palm ash biocomposite films. Journal of Engineering Science, 15(2), 1-16, https://doi. org/10.21315/jes2019.15.2.1.

To link to this article: https://doi.org/10.21315/jes2019.15.2.1

\begin{abstract}
Utilisation of oil palm ash (OPA) in plastic packaging is concerned to environment-friendly, improving performance, and saving the costs of plastics. This study further discussed and compared the properties of un-plasticised polyvinyl alcohol (PVOH)/OPA (80/20) films with PVOH/OPA (80/20) film plasticised with glycerol and urea at different concentrations. Glycerol-plasticised PVOH/OPA (80/20) film showed a decrease of tensile strength but an increase of elongation at break, whereas ureaplasticised film showed gradual increase of both tensile strength and elongation at break when concentration of plasticising agents was increased. This is due to the extensive hydrogen bonding and formation of stable dimeric structure with the addition of urea to PVOH/OPA (80/20) films, which was confirmed by the Fourier transform infrared (FTIR) spectroscopy analysis. In water absorption measurement, the increased concentration of plasticising agent exhibited a decreased water uptake percentage. Both plasticised PVOH/ OPA (80/20) films showed substantial weight loss in natural soil burial study but ureaplasticised films had lower weight loss as compared to glycerol-plasticised films at similar plasticiser concentration. Thermal analysis proved the increase of segmental mobility of polymeric chain in glycerol-plasticised film by showing lower glass transition temperature $\left(T_{g}\right)$, while urea-plasticised films exhibited higher $T_{g}$ due to urea solidification and better interfacial interaction with the hydroxyl group of PVOH and OPA. Also, urea-plasticised films showed higher decomposition temperature than glycerol-plasticised films.
\end{abstract}

Keywords: environment-friendly, tensile properties, water absorption, natural soil burial, thermal 


\section{INTRODUCTION}

Inevitably, synthetic plastic has brought many advantages to mankind. It has become indispensable to human life. However, major environmental problems such as landfilling and damage to the marine environment are mainly caused by uncontrolled disposal of non-degradable plastic packaging. The excellent resistance of synthetic plastic against biological degradation has become a serious concern. ${ }^{1}$ Owing to the severe environmental problem, a recent trend indicates the significant developments on biodegradable plastics, not only novel design strategies, but also comparably good performance.

Polyvinyl alcohol (PVOH) can be synthesised via the non-petroleum route. It is produced from saponification of polyvinyl acetate, and the grading for PVOH can range from partially hydrolysed to fully hydrolysed grade. Properties such as strength, water solubility, and thermal characteristics are dependent on the degree of crystallinity as well as degree of hydrolysis. It is non-toxic and will biodegrade under certain conditions. ${ }^{2}$ Besides, it has excellent film forming ability, which has resulted in its broad industrial uses such as textile sizing, hospital laundry bags, paper coatings, solution cast films, etc. ${ }^{3}$ However, cost saving is vital in developing the PVOH films that can compete with the synthetic films in commercial applications.

On the other hand, extraction of the oil from fresh oil palm fruitlets requires separation of the fruitlets from empty fruit bunches prior to further processing. These empty fruit bunches, which consist of fibres and shells, are often used as boiler fuel by palm oil mill plants to produce steam for electricity generation and palm oil extraction. ${ }^{4}$ The resulting ash after combustion in the boiler is referred to as oil palm ash (OPA) and normally left unused.

Polymer blending is an efficient method because the polar functional group of PVOH can form good compatibility with other polar polymers. In conjunction with the green environmental policy, it is preferable to incorporate industrial agricultural wastes such as OPA in biodegradable polymers such as PVOH to produce eco-sustainable composites. Meanwhile, plasticisers are required to produce the flexible cast blended films. ${ }^{5,6}$

The aim of this study was to assess the potential of glycerol and urea as a plasticising agent in PVOH/OPA cast blended films, not only in terms of tensile properties, infrared spectra, water absorption, but also degradation behaviour under thermal and natural soil burial conditions. 


\section{EXPERIMENTAL DETAILS}

\subsection{Materials}

The PVOH, 99+\% hydrolysed with a molecular weight average of 89,000-98,000 $\mathrm{g} \mathrm{mol}^{-1}$ and density of $1.269 \mathrm{~g} \mathrm{~cm}^{-3}$, was purchased from SigmaAldrich (M) Sdn. Bhd. (Petaling Jaya, Malaysia) with product number and batch number of 341584 and \#21897 LJ, respectively. Meanwhile, OPA was collected from United Oil Palm Mill Industry Sdn. Bhd. located in Nibong Tebal, Pulau Pinang. The collected OPA particles were sieved with a $75 \mu \mathrm{m}$ sized mesh to separate the unburned residues and larger particles such as sand and pebbles, followed by oven-drying at $80^{\circ} \mathrm{C}$ for $24 \mathrm{~h}$ to expel moisture prior to further use. Commercial plasticising agents i.e. glycerol was purchased from Systerm (Shah Alam, Malaysia), whereas urea was purchased from Nacalai Tesque, Inc. (Kyoto, Japan).

\subsection{Film Preparation}

Calculated amount of PVOH/OPA aqueous solution (10 w/v \%) was prepared by dissolving PVOH/OPA in $100 \mathrm{~mL}$ deionised water. The PVOH was first heated on a hot plate stirrer with a magnetic bar by constant stirring at a temperature of $90^{\circ} \mathrm{C}$ until the PVOH was fully dissolved. OPA was then added and stirring continued for another $2 \mathrm{~h}$, followed by the addition of the plasticising agent, i.e. glycerol or urea at 5, 10, 15, and $20 \mathrm{wt} . \%$ to the PVOH/OPA aqueous solution and further heated for another $1 \mathrm{~h}$. The homogenous plasticised PVOH/ OPA aqueous solution was poured onto a cleaned glass plate, which was placed on a levelled flat surface and the casted solution was dried overnight using an oven (model: Memmert, Schwabach, Germany) until constant weight was obtained. The cast plasticised films were then kept in sealed polyethylene bags and stored in a desiccator for two days prior to any characterisation.

\subsection{Evaluation of Tensile Properties}

The tensile test was performed using Light-Weight Tensile Tester (Tinius Olsen, Salfords, UK) according to ASTM D638 Plastic Tensile Strength Test. ${ }^{7}$ The film was cut into dumbbell shape using a dumbbell cutter (Leader Technology Scientific [M] Sdn. Bhd., Balakong, Malaysia). Five dumbbell-shaped specimens were cut for each composition and the thickness of each dumbbell-shaped specimen (average thickness around $0.10 \mathrm{~mm}$ ) was measured using a thickness gauge (Mitutoyo Corporation, Kanagawa, Japan). The film was subjected to $450 \mathrm{~N}$ load cell, 1,200 $\mathrm{mm}$ of extension range; with $25 \mathrm{~mm}$ of gauge length and crosshead 
speed of $20 \mathrm{~mm} \mathrm{~min}^{-1}$ until the fracture of specimen. All tests were conducted at room temperature and average values for tensile strength and elongation at break of five repeated tests were summarised for each composition from a stress-strain curve.

\subsection{Fourier Transform Infrared (FTIR) Spectroscopy}

The chemical bonding of plasticised film was characterised with FTIR spectrophotometer (Perkin Elmer Spectrum: model RX1, Norwalk, CT, USA). Prior to the FTIR analysis, the film was oven-dried to remove moisture. Selected film for each composition was cut into smaller size and was mounted directly to the sample holder for analysis. Spectrum was recorded after scanning the background. The spectrum was scanned from 4,000 to $600 \mathrm{~cm}^{-1}$ with 16 number of scan, 4.0 $\mathrm{cm}^{-1}$ resolution, $1.0 \mathrm{~cm}^{-1}$ interval, and recorded in transmittance $(\% \mathrm{~T})$.

\subsection{Water Absorption Measurement}

Five specimens were weighed $\left(W_{i}\right)$ before fully immersed in distilled water until equilibrium was reached after $24 \mathrm{~h}$. The moisture on surface was then removed using filter paper and the weight gained $\left(W_{f}\right)$ was measured. The percentage of water absorption in film was calculated as shown in Equation 1. The average value was calculated from five duplicate specimens.

$$
W_{a}=\frac{\left(W_{f}-W_{i}\right)}{W_{i}} \times 100 \%
$$

where $W_{a}$ is the percentage of water absorption by the film, $W_{f}$ is the weight of film at the absorbing equilibrium, and $W_{i}$ is the initial dried weight of the film.

\subsection{Natural Soil Burial}

The degradation behaviour of plasticised film was determined by burying the specimens in compost soil obtained from Jaya Pot Enterprise (Kuala Langat, Malaysia). The composition of compost soil was $0.15 \% \mathrm{~N}, 0.50 \% \mathrm{P}, 0.30 \% \mathrm{~K}$, and $0.15 \% \mathrm{MgO}$. Prior to the soil burial test, the specimens were dried at $60^{\circ} \mathrm{C}$ until constant weight to expel the moisture. Five dumbbell-shaped specimens from each composition were then buried in soil at a depth of $3 \mathrm{~cm}$ and the soil was kept by sprinkling water at 1-day intervals to maintain the humidity. The natural soil burial was carried out for one month and the weight loss was recorded at one week's intervals. The specimen was carefully washed with deionised water to remove attached soil and taped using filter paper followed by drying the degraded film at 
$60^{\circ} \mathrm{C}$. After that, the weight of specimen was weighed and the weight loss of the films over time was examined using Equation 2. The average value was calculated from five duplicate specimens.

$$
\text { Weight loss }(\%)=\frac{w_{i}-w_{d}}{w_{i}} \times 100
$$

where $w_{i}$ is initial dry weight of specimen and $w_{d}$ is weight of specimen after burial test.

\subsection{Thermal Characterisation}

Thermal characterisation of the plasticised films was determined using differential scanning calorimeter (model: DSC823e, Mettler Toledo, Schwerzenbach, Switzerland). About 7-8 $\mathrm{mg}$ of sample was weighed and hermetically sealed in an aluminium crucible. An empty aluminium crucible was used as reference cell. The melting and crystallisation behaviours were analysed at a heating rate of $10^{\circ} \mathrm{C} \mathrm{min}^{-1}$ from $25^{\circ} \mathrm{C}$ to $250^{\circ} \mathrm{C}$, annealed at $250^{\circ} \mathrm{C}$ for $1 \mathrm{~min}$ to eliminate thermal history, then cooled from $250^{\circ} \mathrm{C}$ to $25^{\circ} \mathrm{C}$. After cooling, the second heating run was performed and used for the evaluation. The temperature profile was programmed under the nitrogen gas at a purge rate of 50 $\mathrm{mL} \min ^{-1}$ using immersion cooler (model: TC45, Huber, Offenburg, Germany) to avoid the thermo-oxidative degradation of the PVOH/OPA film. The melting temperature $\left(T_{m}\right)$, crystallisation temperature $\left(T_{c}\right)$, and glass transition temperature $\left(T_{g}\right)$ was obtained from the differential scanning calorimetry (DSC) thermogram. $T_{g}$ corresponded to the temperature where a baseline inflection occurred while $T_{m}$ was taken as the temperature at maximum endothermic melting peak from the second heating run.

Meanwhile, the thermal degradation analysis was carried out using thermogravimetric analysis (TGA) (model: TGA/SDTA851 ${ }^{\mathrm{e}}$, Mettler Toledo, Schwerzenbach, Switzerland). About 4-5 $\mathrm{mg}$ of sample was weighed into a hermetically sealed aluminium crucible and placed inside a tube of furnace and heated from $25^{\circ} \mathrm{C}$ to $700^{\circ} \mathrm{C}$ at a heating rate of $10^{\circ} \mathrm{C} \mathrm{min} \mathrm{m}^{-1}$ under nitrogen flow

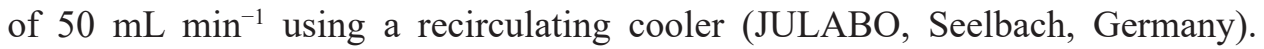
The weight change of sample as a function of temperature was recorded. The temperature at certain weight loss of film and percentage of residue were recorded. 


\section{RESULTS AND DISCUSSION}

\subsection{Evaluation of Tensile Properties}

Figure 1 shows the tensile strength and percentage elongation at break of PVOH/OPA (80/20) film using different plasticising agents, i.e. glycerol and urea at different concentrations. It is speculated that as plasticising agent concentration increases, tensile strength decreases, while elongation at break increases significantly. However, among both the plasticising agents, the trend only applied for glycerol plasticising agent.

The result of Figure 1 shows that urea plasticising agent generally increases the tensile strength with increasing concentrations of urea. The addition of urea markedly had positive impact on the tensile strength and elongation at break of the PVOH/OPA films. Similar phenomenon was found by Wang et al. and Mo and Sun for plastic made from modified soy protein isolate and $\mathrm{PVOH} / \mathrm{xylan}$ cast films. ${ }^{8,9}$ This may be due to the possibility of interaction between hydroxyl group of PVOH and amine group of urea, as shown in Equation 3. This will be further proven by the FTIR analysis, which is leading to increasing tensile strength.

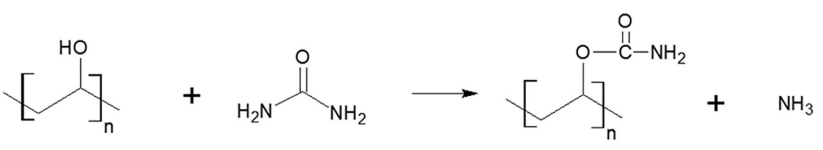

\subsection{FTIR Spectroscopy}

Figures 2 and 3 show the FTIR spectra of glycerol-plasticised PVOH/ OPA (80/20) film and urea-plasticised PVOH/OPA (80/20) film at different concentrations of plasticising agents, respectively. The addition of glycerol as plasticising agent caused the absorption bands of the hydroxyl groups to shift from $3,254 \mathrm{~cm}^{-1}$ to $3,264 \mathrm{~cm}^{-1}$. The shifting in the peak can be explained by a disruption of hydrogen bonding within PVOH polymeric chains due to glycerol addition. Another way of saying is the elasticity of cast blended film can be improved by the addition of glycerol. However, for urea-plasticised PVOH/OPA (80/20) film, there was a noticeable difference between the absorption bands of hydroxyl group though both urea and glycerol serve as plasticising agents as reported by previous researchers. $^{6,10}$ The addition of urea would cause the hydroxyl group of PVOH/ OPA (80/20) film to broaden, especially upon $10 \mathrm{phr}$ addition of urea. This may be due to the shifting of hydrogen bonding and is associated with the N-H absorption. As with the amine group of urea, there was an additional peak clearly observed in 15 and 20 phr urea-plasticised PVOH/OPA film at 3,424.4 and 3,427.3 $\mathrm{cm}^{-1}$, 
respectively. As reported by Coates, the impact of this overlap would produce significant band broadening and lower frequency. ${ }^{11}$ This can be explained that the addition of urea will result in extensive hydrogen bonding and forming of a stable dimeric structure in the $\mathrm{PVOH} / \mathrm{OPA}(80 / 20)$ film. Besides, a characteristic feature of carboxylate functional group and $\mathrm{C}=\mathrm{O}$ of amides primary with group frequency at 1,578 and $1,675 \mathrm{~cm}^{-1}$, respectively, were observed in $20 \mathrm{phr}$ ureaplasticised PVOH/OPA films. This indicated the possibility of interaction between hydroxyl group of $\mathrm{PVOH}$ and amine group of urea and thus resulting in higher tensile strength.
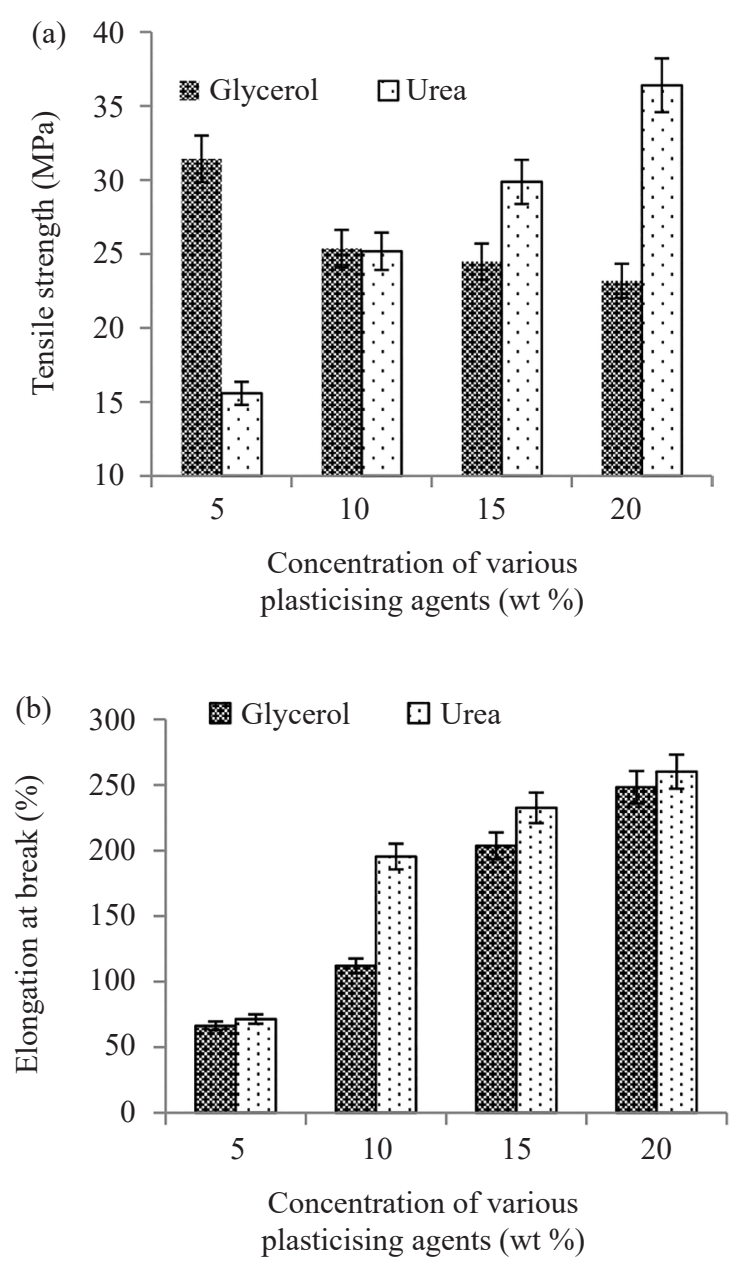

Figure 1: (a) Tensile strength (MPa) and (b) elongation at break (\%) for PVOH/OPA $(80 / 20)$ blend with glycerol and urea plasticising agents. 


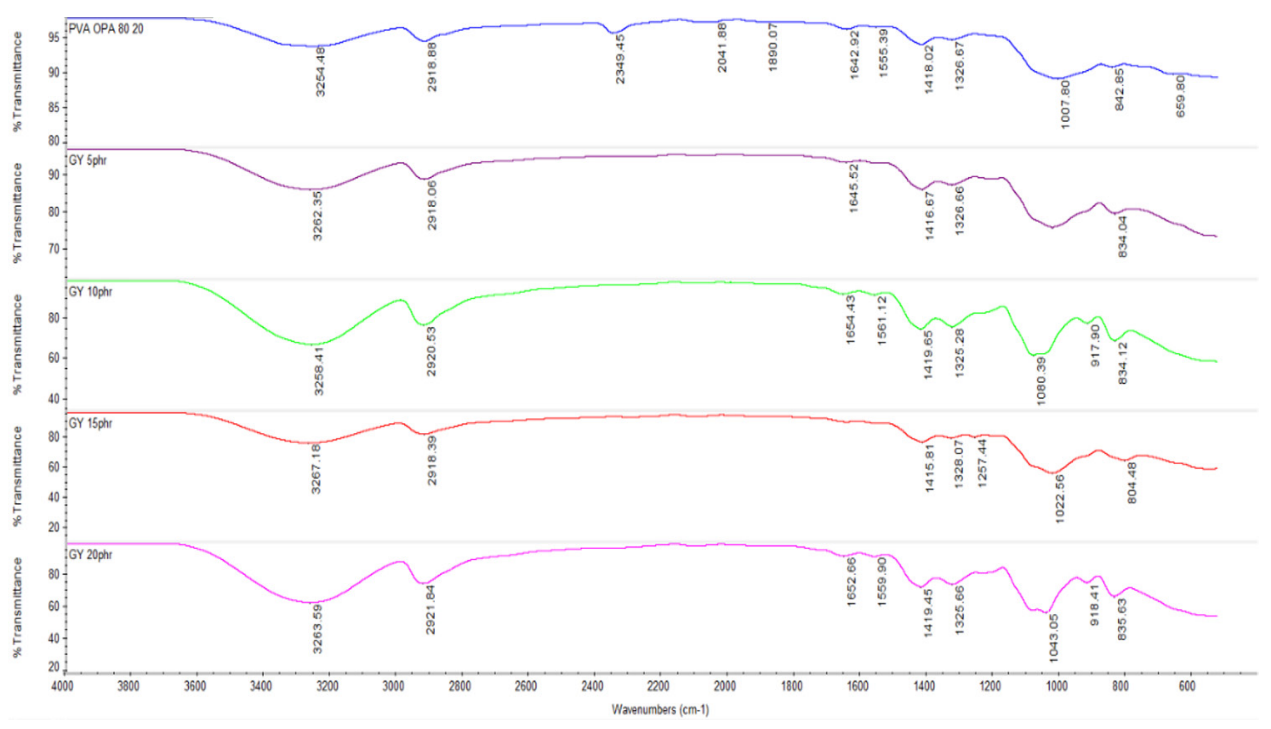

Figure 2: The FTIR spectrum of glycerol-plasticised PVOH/OPA (80/20) films at different concentrations of glycerol.

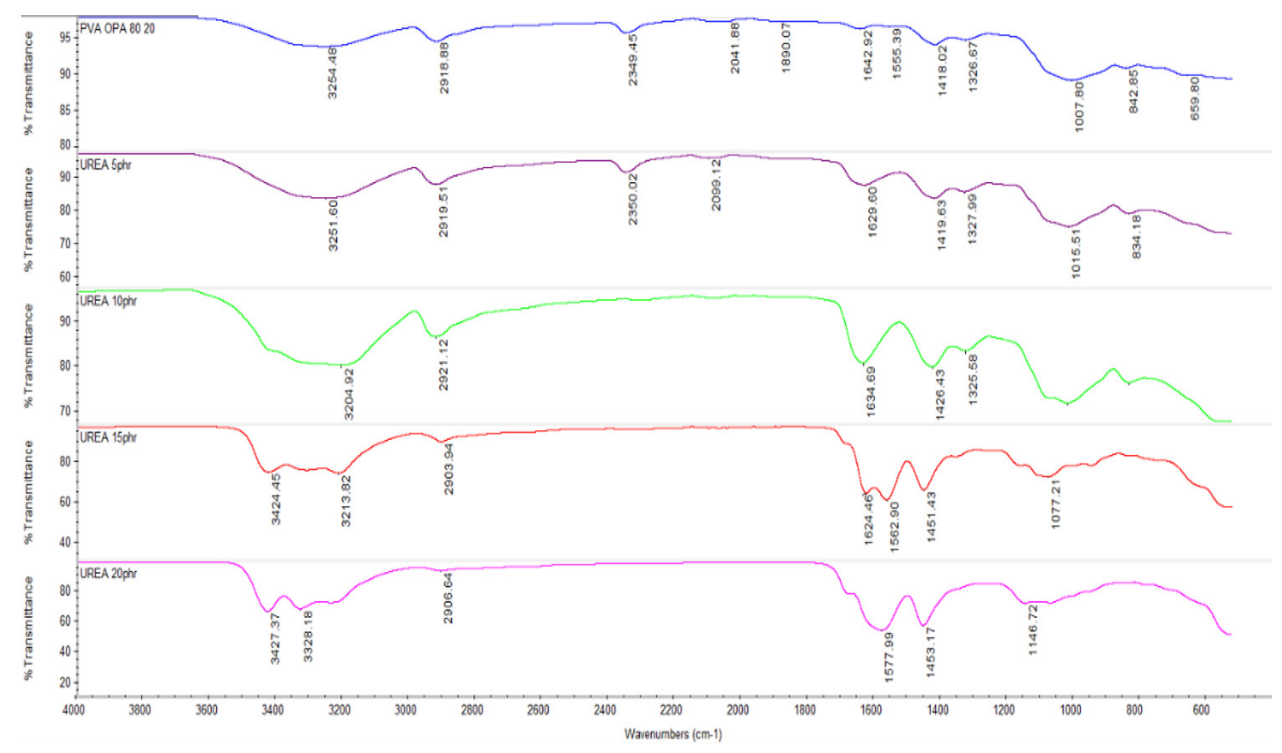

Figure 3: The FTIR spectrum of urea-plasticised PVOH/OPA (80/20) films at different concentrations of urea. 


\subsection{Water Absorption Measurement}

Figure 4 displays the water affinity of glycerol-plasticised and ureaplasticised PVOH/OPA 80/20 films. As reported by a previous study, with increasing glycerol concentration, the moisture content increased. ${ }^{12}$ However, in this study, all the plasticised blended cast films showed a decrease in the percentage of water uptake with increase in both plasticising agents (glycerol and urea). Similar finding was observed by Huang et al. when they studied glycerol concentration in the protein-starch based plastics. ${ }^{13}$ The reason for this may account to the fact that plasticising agents are able to occupy the space surrounding within the polymeric chain of $\mathrm{PVOH}$ and may form interaction between the $\mathrm{PVOH}$ molecules and thus resulted in the number of contact between the PVOH molecules and water molecules may restricted.

At a similar concentration of plasticising agents tested, the PVOH/OPA films plasticised with glycerol had higher water uptake as compared to those of urea-plasticised PVOH/OPA films. As mentioned earlier, the water uptake decreased as the plasticising concentrations increased due to better interaction between plasticising agents and $\mathrm{PVOH}$ molecules and less active site for water binding. This may be due to urea molecules having two amino groups, which can form better interaction with $\mathrm{PVOH}$ as compared to glycerol, thus resulting in lesser water uptake.

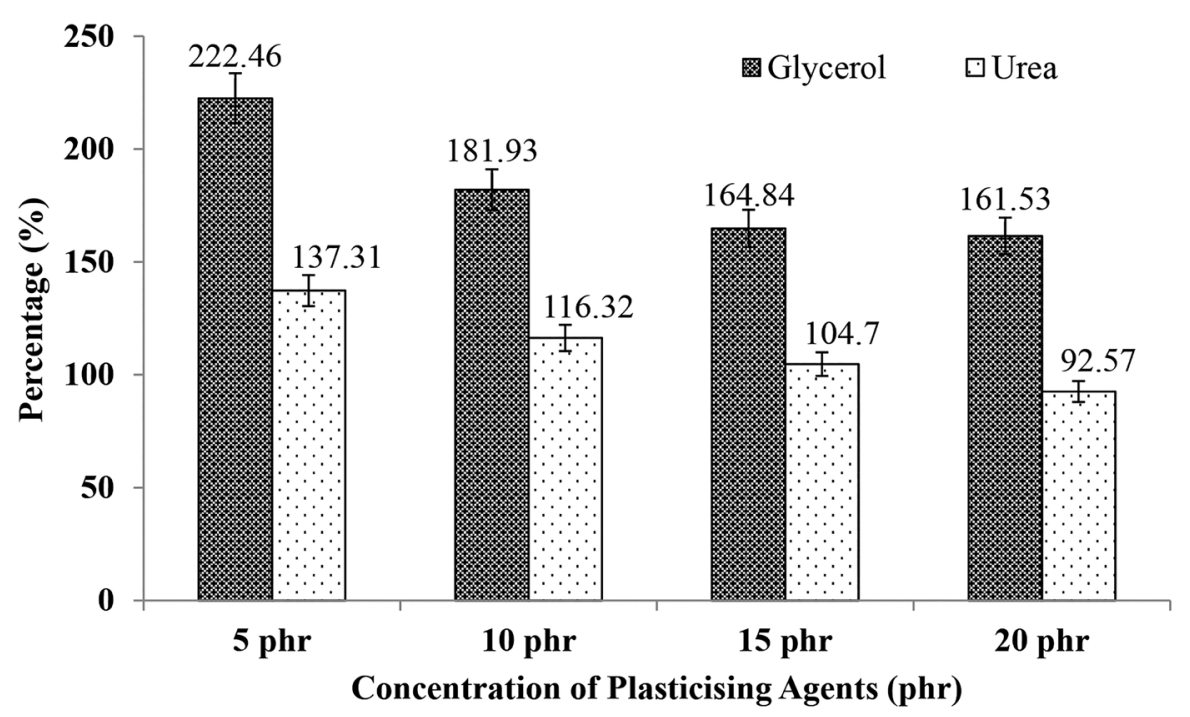

Figure 4: Comparison of water uptake in PVOH/OPA (80/20) films plasticised with glycerol and urea. 


\subsection{Natural Soil Burial}

A set of degraded samples were removed from the soil and the measurement of degradation percentage based on weight loss was determined every week for up to four weeks. Figures 5 and 6 show the weight loss percentage of the glycerolplasticised and urea-plasticised PVOH/OPA (80/20) film, respectively, after being buried in soil within four weeks. Soil burial test showed a 10\%-30\% weight loss, which varies depending on the concentration and type of plasticising agents. It is manifested that there is a substantial increase of weight loss for all the plasticised PVOH/OPA (80/20) blended cast films as either glycerol or urea concentration increased.

By comparing Figures 5 and 6, the weight loss of urea-plasticised PVOH/ OPA (80/20) films were slightly lower as compared to the glycerol-plasticised PVOH/OPA (80/20) films. This may attribute to the addition of urea that resulted in extensive hydrogen bonding and forming a stable dimeric structure in the PVOH/OPA (80/20) film than that of glycerol-plasticised PVOH/OPA (80/20) films. Formation of stronger dimeric structure in PVOH/OPA with the addition of urea results in lower degradation of urea plasticised $\mathrm{PVOH} / \mathrm{OPA}$ as compared to glycerol plasticised $\mathrm{PVOH} / \mathrm{OPA}$ at similar plasticising agent concentration.

Dweek 1 Bweek 2 ■week 3 国week 4

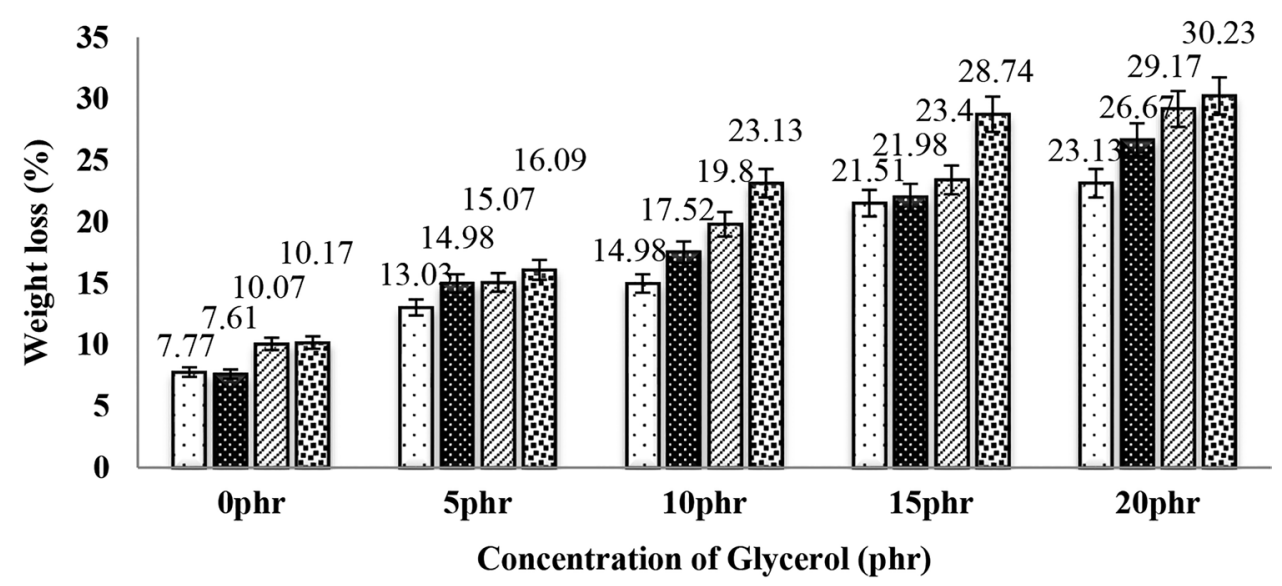

Figure 5: Weight loss of the glycerol-plasticised PVOH/OPA (80/20) cast films after burial test in soil for four weeks. 


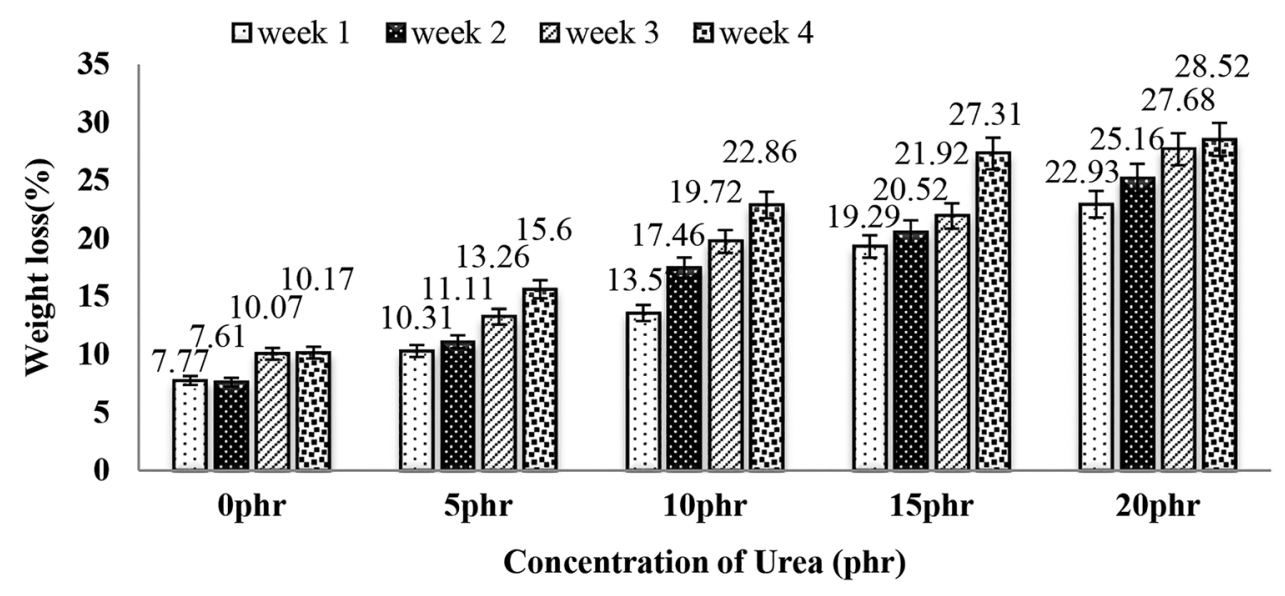

Figure 6: Weight loss of urea-plasticised PVOH/OPA (80/20) cast films after burial test in soil for four weeks.

\subsection{Thermal Characterisation}

\subsubsection{Differential scanning calorimetry (DSC)}

Table 1 summarises the thermal behaviour of un-plasticised PVOH/ OPA (80/20) films and PVOH/OPA (80/20) films plasticised with glycerol and urea at $10 \mathrm{phr}$. It is manifested that addition of plasticising agents would cause the $T_{g}$ of $\mathrm{PVOH} / \mathrm{OPA}(80 / 20)$ films to change. Different observations were made for glycerol-plasticised PVOH/OPA (80/20) film and urea-plasticised $\mathrm{PVOH} /$ OPA (80/20) film. The concepts of interfacial interaction and molecular mobility have been useful to explain the dramatic change in $T_{g}{ }^{14}$ The glycerol-plasticised $\mathrm{PVOH} / \mathrm{OPA}$ (80/20) film exhibited lower $T_{g}$ than that of un-plasticised PVOH/OPA (80/20) film. The decrement of $T_{g}$ suggests that the plasticising effect of glycerol increases the segmental mobility of $\mathrm{PVOH}$ and decreases the crystalline region of PVOH by weakening the hydrogen bonding between PVOH. However, the observance of increment in $T_{g}$ of urea-plasticised PVOH/OPA (80/20) film may be due to the urea solidification and better interfacial interaction that restrict the mobility chain of PVOH. The $T_{m}$ and $T_{c}$ of both plasticised films is lowered than in un-plasticised films. This explains that the addition of glycerol and urea does greatly affect the crystallisation rate of $\mathrm{PVOH}$. In the case of urea-plasticised $\mathrm{PVOH} /$ OPA (80/20) film, the addition of urea lowers the $T_{c}$ indicating the retardation of crystallisation rate. This may be due to the urea that bonded with the PVOH and thus diminished the chain regularity as well as increasing the active energy of nucleation. 
Table 1: Thermal characteristics of un-plasticised PVOH/OPA (80/20) film and PVOH/ OPA (80/20) films plasticised with glycerol and urea at $10 \mathrm{phr}$.

\begin{tabular}{lccc}
\hline Samples & $T_{g}\left({ }^{\circ} \mathrm{C}\right)$ & $T_{m}\left({ }^{\circ} \mathrm{C}\right)$ & $T_{c}\left({ }^{\circ} \mathrm{C}\right)$ \\
\hline Un-plasticised PVOH/OPA (80/20) & 79.25 & 218.82 & 198.21 \\
Glycerol-plasticised PVOH/OPA (80/20) & 59.06 & 212.21 & 186.29 \\
Urea-plasticised PVOH/OPA (80/20) & 81.11 & 186.15 & 153.03 \\
\hline
\end{tabular}

\subsubsection{Thermogravimetric analysis (TGA)}

The TGA and derivative thermogravimetry (DTG) profiles for unplasticised and both plasticised PVOH/OPA (80/20) are given in Figure 7 and the detailed variation of $10 \%$ weight loss $\left(T_{-10 \%}\right), 30 \%$ weight loss $\left(T_{-30 \%}\right), 50 \%$ weight loss $\left(T_{-50 \%}\right)$, temperature at maximum weight loss rate $\left(T_{\max I}\right)$, and char residue (\%) are summarised in Table 2. As highlighted in Figure 7(a), the first stage showed a mass loss for drying the samples, either surface or inherent moisture are emitted between $50^{\circ} \mathrm{C}$ and $130^{\circ} \mathrm{C}$. The second stage is due to the thermal decomposition of polymeric component between $200^{\circ} \mathrm{C}$ and $350^{\circ} \mathrm{C}$; however, it is clearly observed that both plasticised $\mathrm{PVOH} / \mathrm{OPA}(80 / 20)$ films showed a weight loss before $200^{\circ} \mathrm{C}$, which suggest is the thermal decomposition of glycerol and urea. The third stage weight loss is due to the further decomposition of polymer blend. The weight loss then tends to equilibrium from $500^{\circ} \mathrm{C}$ to the end of this experiment $\left(700^{\circ} \mathrm{C}\right)$.

According to a previous study, the temperature at the thermal stability was slightly increased and a similar increase in char residue when the concentration of OPA increased due to the better resistance of OPA itself. ${ }^{15}$ By comparison with the plasticised and un-plasticised PVOH/OPA(80/20) films, the plasticised $\mathrm{PVOH} / \mathrm{OPA}$ (80/20) films exhibited lower decomposition temperature than those un-plasticised $\mathrm{PVOH} / \mathrm{OPA}(80 / 20)$ films, especially at $50 \%$ weight loss due to plasticising effects of glycerol and urea. At 10\% and 30\% weight loss, the glycerol-plasticised PVOH/ OPA (80/20) films showed lower thermal decomposition temperature than that of urea-plasticised PVOH/OPA (80/20) films. This may be related to the concept of free volume in the PVOH/OPA (80/20) films. These results clearly suggest the thermal decomposition depend on the types of plasticising agents used and efficiency of mixing and interaction of the plasticising agents with the PVOH/ OPA. Tajuddin et al. postulated that the lower molecular weight plasticising agents can penetrate between the molecular chains effectively when compared to the higher molecular weight plasticising agent such as glycerol. ${ }^{16}$ As discussed in the earlier section, urea can form better interaction with $\mathrm{PVOH}$ than glycerol resulting in lower free volume in urea-plasticised $\mathrm{PVOH} / \mathrm{OPA}$ (80/20) films as compared to glycerol-plasticised PVOH/OPA (80/20) films, which contribute to high thermal stability of PVOH/OPA films. 

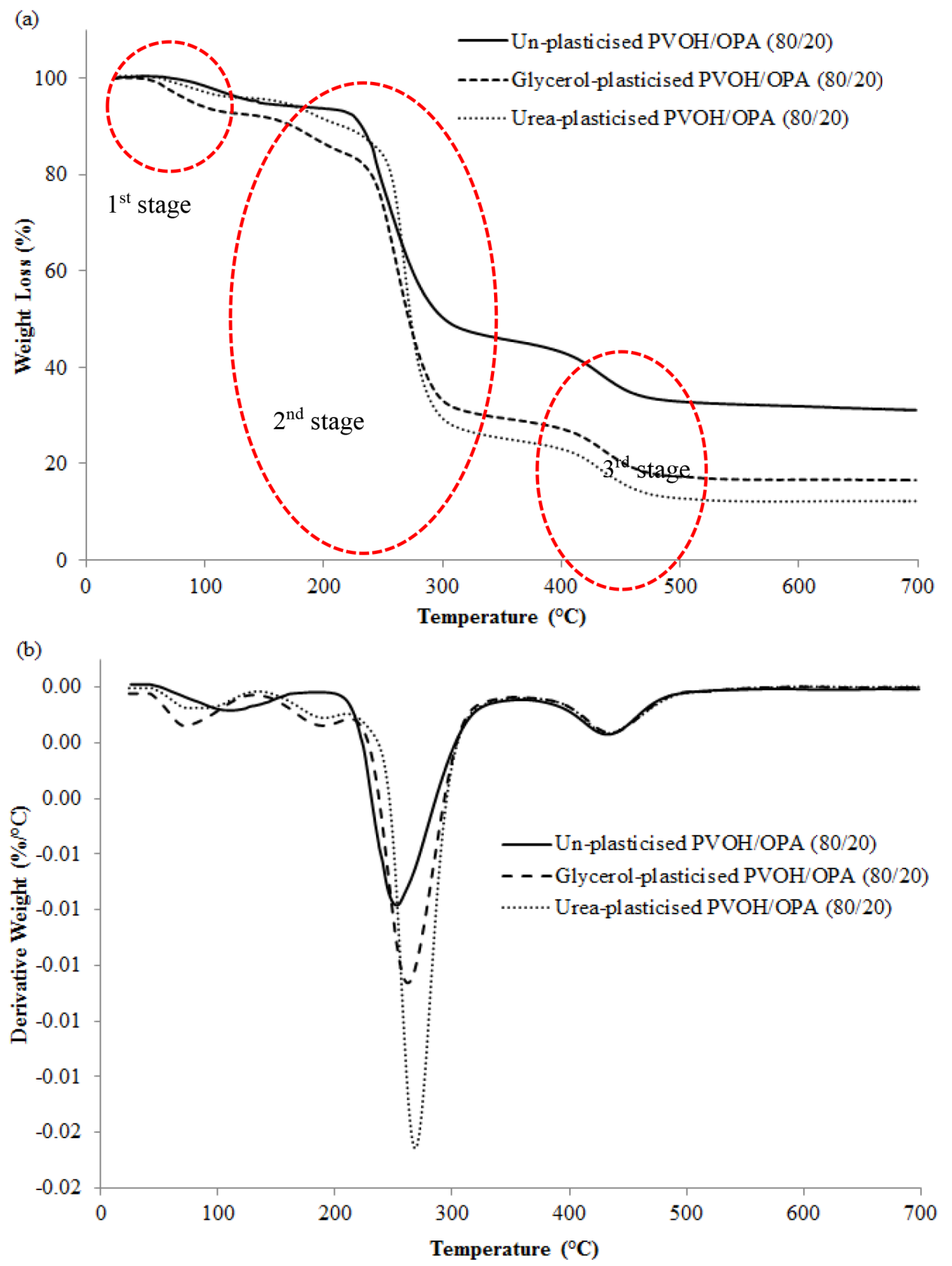

Figure 7: TGA of un-plasticised PVOH/OPA (80/20) and plasticised PVOH/OPA (80/20) with 10 phr of glycerol and urea: (a) TGA and (b) DTG. 
Table 2: TGA of PVA/OPA un-plasticised film and PVA/OPA films plasticised with glycerol and urea at $10 \mathrm{phr}$.

\begin{tabular}{lccccc}
\hline \multirow{2}{*}{ Sample } & \multicolumn{5}{c}{ Decomposition temperature $\left({ }^{\circ} \mathrm{C}\right)$ at certain weight loss percentage $(\%)$} \\
\cline { 2 - 6 } & $T_{-10 \%}\left({ }^{\circ} \mathrm{C}\right)$ & $T_{-30 \%}\left({ }^{\circ} \mathrm{C}\right)$ & $T_{-50 \%}\left({ }^{\circ} \mathrm{C}\right)$ & $T_{\max I}\left({ }^{\circ} \mathrm{C}\right)$ & Char residue $(\%)$ \\
\hline Un-plasticised & 231.5 & 259.4 & 301.1 & 252.2 & 31.13 \\
PVOH/OPA (80/20) & & & & & 16.60 \\
$\begin{array}{l}\text { Glycerol-plasticised } \\
\text { PVOH/OPA (80/20) }\end{array}$ & 174.5 & 253.3 & 271.2 & 262.2 & 12.26 \\
$\begin{array}{l}\text { Urea-plasticised } \\
\text { PVOH/OPA (80/20) }\end{array}$ & 216.5 & 263.8 & 273.7 & 268.6 & \\
\hline
\end{tabular}

Notes: $T_{-10 \%}=$ temperature at $10 \%$ weight loss; $T_{-30 \%}=$ temperature at $30 \%$ weight loss; $T_{-60 \%}=$ temperature at $50 \%$ weight loss; $T_{\max I}=$ temperature at maximum weight loss rate.

\section{CONCLUSION}

This study had evaluated the effect of plasticising agents, i.e. glycerol and urea on PVOH/OPA (80/20) films. The urea-plasticised films showed higher tensile strength than those of glycerol-plasticised PVOH/OPA (80/20) films due to formation of new hydrogen bonding with PVOH/OPA chains through two amide groups. This could be explained by the shifting of the absorption bands in the FITR analysis. Urea-plasticised film had lower water uptake capability and lower burial degradation weight loss than those of glycerol-plasticised $\mathrm{PVOH} /$ OPA (80/20) films. In case of $T_{g}$, urea-plasticised film shows increased of $T_{g}$ while glycerol-plasticised film showed a decreased of $T_{g}$. The depression of $T_{g}$ is due to the increase in the segmental mobility of $\mathrm{PVOH}$ chains and vice versa. Also, TGA analysis revealed that the urea-plasticised $\mathrm{PVOH} / \mathrm{OPA}(80 / 20)$ film showed higher thermal decomposition temperature than that of glycerol-plasticised $\mathrm{PVOH} / \mathrm{OPA}$ (80/20) film.

\section{ACKNOWLEDGEMENTS}

This work is financially supported by the Universiti Tunku Abdul Rahman Research Fund (Project No. IPSR/RMC/UTARRF/2015-C2/O03). Besides, the authors would like to acknowledge United Oil Palm Mill Industries Sdn. Bhd. for providing the oil palm ashes for this project. 


\section{REFERENCES}

1. Luckachan, G. E. \& Pillai, C. K. S. (2011). Biodegradable polymers - A review on recent trends and emerging perspectives. J. Polym. Environ., 19(3), 637-676, https://doi.org/10.1007/s10924-011-0317-1.

2. Wang, N., Zhao, L., Zhang, C. \& Li, L. (2016). Water states and thermal processability of boric acid modified poly (vinyl alcohol). J. Appl. Polym. Sci., 133(13), 43246(1-7), https://doi.org/10.1002/app.43246.

3. Tang, X. \& Alavi, S. (2011). Recent advances in starch, polyvinyl alcohol based polymer blends, nanocomposites and their biodegradability. Carbohyd. Polym., 85(1), 7-16, https://doi.org/10.1016/j.carbpol.2011. 01.030 .

4. Ooi, Z. X., Ismail, H. \& Abu Bakar, A. (2014). Chemically modified oil palm ash-filled natural rubber composites and its properties. Polym. Composite., 35(4), 691-697, https://doi.org/10.1002/pc.22712.

5. Vieira, M. G. A., da Silva, M. A., dos Santos, L. O. \& Beppu, M. M. (2011). Natural-based plasticizers and biopolymer films: A review. Eur. Polym. J., 47(3), 254-263, https://doi.org/10.1016/j.eurpolymj.2010.12.011.

6. Ooi, Z. X., Ismail, H., Bakar, A. A. \& Aziz, N. A. A. (2012). The comparison effect of sorbitol and glycerol as plasticizing agents on the properties of biodegradable polyvinyl alcohol/rambutan skin waste flour blends. Polymer. Plast. Tech. Eng., 51(4), 432-437, https://doi.org/10.108 0/03602559.2011.639827.

7. ASTM International. (2014). ASTM D638-14. Tensile properties of plastics. West Conshohocken, PA: ASTM International.

8. Wang, S., Ren, J., Kong, W., Gao, C., Liu, C., Peng, F. \& Sun, R. (2014). Influence of urea and glycerol on functional properties of biodegradable PVA/xylan composite films. Cellulose, 21(1), 495-505, https://doi. org/10.1007/s10570-013-0091-4.

9. Mo, X. \& Sun, X. (2001). Thermal and mechanical properties of plastics molded from urea-modified soy protein isolates. J. Am. Oil Chem. Soc., 78(8), 867-872, https://doi.org/10.1007/s11746-001-0357-1.

10. Wang, J. L., Cheng, F. \& Zhu, P. X. (2014). Structure and properties of urea-plasticized starch films with different urea contents. Carbohyd. Polym., 101, 1109-1115, https://doi.org/10.1016/j.carbpol.2013.10.050.

11. Coates, J. (2000). Interpretation of infrared spectra: A practical approach. In R. A. Meyers (ed.), Encyclopedia of analytical chemistry. Chichester, UK: John Wiley \& Sons Ltd., 10881-10882. 
12. Aranda-García, F. J., González-Núñez, R., Jasso-Gastinel, C. F. \& Mendizábal, E. (2015). Water absorption and thermomechanical characterization of extruded starch/poly (lactic acid)/agave bagasse fiber bioplastic composites. Int. J. Polym. Sci., Article ID 343294, 1-7, https://doi.org/10.1155/2015/343294.

13. Huang, H. C., Chang, T. C. \& Jane, J. (1999). Mechanical and physical properties of protein-starch based plastics produced by extrusion and injection molding J. Am. Oil Chem. Soc., 76(9), 1101-1108, https://doi. org/10.1007/s11746-999-0210-4.

14. Overney, R., Buenviaje, C., Luginbühl, R. \& Dinelli, F. (2000). Glass and structural transitions measured at polymer surfaces on the nanoscale. J. Therm. Anal. Calorim., 59(1-2), 205-225, https://doi. org/10.1023/A:1010196214867.

15. Ooi, Z. X., Ismail, H. \& Abu Bakar, A. (2015). Characterization of oil palm ash (OPA) and thermal properties of OPA filled natural rubber compounds. J. Elastomers Plast., 47(1), 13-27, https://doi. org/10.1177/0095244313489901.

16. Tajuddin, S., Xie, F., Nicholson, T. M., Liu, P. \& Halley, P. J. (2011). Rheological properties of thermoplastic starch studied by multipass rheometer. Carbohyd. Polym., 83(2), 914-919, https://doi.org/10.1016/j. carbpol.2010.08.073. 